\title{
Plasma lipid, lipoprotein and apolipoprotein profiles in Nigerian university athletes and non-athletes
}

\author{
O. O. Oyelola PhD and M. A. Rufai MB ChB \\ Department of Chemical Pathology and Institute of Physical Education, Obafemi Awolowo University, Ile-Ife, \\ Osun State, Nigeria
}

\begin{abstract}
The fasting plasma lipid, lipoprotein and apolipoprotein profiles were determined in 14 healthy Nigerian male athletes and controls matched for sex and anthropometric parameters. The mean levels of total cholesterol $(P<0.05)$, low-density lipoprotein (LDL) cholesterol, apolipoprotein (apo) AII and E were significantly lower $(P<0.01)$ in the athletes than in the controls. However, there were no statistically significant differences $(P>0.05)$ between the mean values of the plasma triglycerides, high-density lipoprotein (HDL), very low-density lipoprotein (VLDL) cholesterol, apo AI, B, Lp(a), LpA1 and CIII:NonB respectively for the athletes and controls. A priori, the potential effect on cardiovascular disease (CVD) risk was also compared using three predictor ratios - total cholesterol: HDL cholesterol (TC:HDL), LDL cholesterol: HDL cholesterol and apo B:AI. The mean of the three ratios was lower in the athletes than in the controls; however, the differences were not statistically significant $(P>0.05)$. Based on our data, exercise appears to decrease the TC:HDL ratio in the athletes by lowering LDLcholesterol, while the HDL-cholesterol is unaffected. We conclude that physical activity has salutary effects on the lipid, lipoprotein and apolipoprotein profiles of healthy Nigerian men.
\end{abstract}

Keywords: Physical activity, lipids, lipoproteins, apolipoproteins, cardiovascular disease

Research interest in lipids and lipoprotein metabolism has increased due to the establishment of the roles played by lipids, lipoproteins and apolipoproteins in the development of cardiovascular disease (CVD) ${ }^{1-5}$. Plasma lipid and lipoprotein levels have been shown to be influenced by age, sex, socioeconomic status, genetics, race, diet, cigarette smoking, coffee and alcohol intake, and medication as well as habitual and leisure time physical activity ${ }^{6-11}$.

Increased physical activity has been reported to produce favourable changes in the lipid and lipoprotein profiles $12-15$. These changes are also influenced by sex, diet, intensity of exercise, body weight and percentage body fat ${ }^{8,15-19}$.

In black Africans, there is a relatively lower level of risk factors and incidence of CVD when compared

Address for correspondence: $\mathrm{O}$. O. Oyelola PhD, Rockefeller Foundation Fellow, The Christ Hospital, Cardiovascular Research Center, 2350 Auburn Avenue, Cincinnati, Ohio 45219, USA

(C) 1993 Butterworth-Heinemann Ltd 0306-3674/93/040271-04 with Caucasians and other Blacks in industrialized countries $^{20-22}$. Less severe atherosclerotic lesions of the aorta, coronary and cerebral arteries have also been reported in black Africans ${ }^{23-26}$. There are presently few published reports on lipids in black athletes ${ }^{27,28}$. These studies examined the effect of exercise on body fats, cholesterol and triglyceride. Therefore, we examine in detail the plasma lipid, lipoprotein and apolipoprotein profiles, and three CVD predictor ratios ${ }^{1-4}$ in some Nigerian athletes and a matched control group.

\section{Subjects and methods}

Fourteen healthy male athletes (mean(s.d.) age 22(4); range 18-28 years) at the Institute of Physical Education, Obafemi Awolowo University, Ile-Ife, Nigeria and 14 healthy non-athletes (mean age 24(5); range 18-31 years) at the same university served as controls. All participants gave their consent before the study. The athletes were all well trained, élite short/medium distance $(100,200$ or $400 \mathrm{~m})$ runners of the university team, and they had been running for 4-8 years. They had been undergoing moderate physical training (running 5-10 km) 3-5 days per week for about 4 weeks before the study.

The athletes and the control group were matched $(P>0.05)$ for age, weight, height, body mass index (BMI) determined by a nomograph ${ }^{29}$, and systolic and diastolic blood pressure (Table 1). The subjects were all non-smokers and were not taking any medication at the time of study. They were all on the same university regular diet, and were also told to abstain from alcoholic beverages for at least 2 weeks before sampling.

Table 1. Characteristics of the athletes and controls

\begin{tabular}{lccl}
\hline & Athletes & Control & $P$ \\
\hline Age (years) & $22(4)$ & $24(5)$ & n.s.* \\
Weight $(\mathrm{kg})$ & $65(9)$ & $61(6)$ & n.s. \\
Height $(\mathrm{cm})$ & $172(9)$ & $168(8)$ & n.s. \\
Body mass index $\left(\mathrm{kg} \mathrm{m}^{-2}\right)$ & $22(2)$ & $22(3)$ & n.s. \\
Blood pressure $\left(\mathrm{mmHg}^{2}\right)$ & $117(8)$ & $120(13)$ & n.s. \\
$\quad$ Systolic & $79(11)$ & $79(6)$ & n.s. \\
Diastolic & & & \\
\hline
\end{tabular}

Values are mean(s.d.); ${ }^{*}$ n.s., Not statistically significant $(P>0.05)$ 


\section{Collection of blood samples}

Fasting blood samples (10-12 h after the last meal) were collected from each subject (about $12 \mathrm{~h}$ after physical exercise in the athletes) into sodium-EDTA anticoagulant. The plasma was separated within $2 \mathrm{~h}$ of collection in a refrigerated centrifuge (Damon/IEC B-20A) precooled to $4^{\circ} \mathrm{C}$ at $1500 \mathrm{~g}$ for $15 \mathrm{~min}$, and stored at $-80^{\circ} \mathrm{C}$ before analysis.

\section{Plasma lipids and lipoprotein assay}

Plasma total cholesterol and HDL-cholesterol and triglycerides were analysed by an automated microenzymatic procedure on a Hitachi 737 chemistry analyser as described by Steiner $e t a l .^{30}$ at the Medical Research Laboratories, Cincinnati, Ohio, USA. The laboratory maintained CDC-NHLBI Part 3 Standardization $^{31}$ for all three lipid parameters. HDL was isolated using the modified heparin- $2 \mathrm{M} \mathrm{MnCl}_{2}$ procedure $^{32}$. LDL-cholesterol was calculated by the Friedewald equation ${ }^{33}$.

\section{Plasma apolipoprotein assay}

The apolipoproteins (apo) AI, AII, B and E were analysed using competitive enzyme-linked immunoabsorbent assay (ELISA) procedures utilizing a monoclonal antibody against each apolipoprotein ${ }^{34-36}$. Apo Lp(a) was also determined by competitve ELISA using a monospecific rabbit antiserum to $\operatorname{Lp}(a)^{37}$.

\section{Plasma lipoprotein particle assay}

Lipoprotein particles consisting of apo AI only (LpAI) were determined by the differential electroimmunoassay (EIA) technique ${ }^{38}$ using a Hydragel LpAI kit (Sebia, Issy-les-Moulineaux, France). Total apo CIII was also measured by EIA $^{39}$ with a Hydragel LPCIII kit (Sebia, Issy-les-Moulineaux, France). The amount of plasma apo CIII not associated with apo B containing apoproteins (LpCIII:NonB) was measured by the same EIA for total LPCIII after the precipitation of apo B containing lipoproteins with a specific apo $B$ antiserum. LpCIII: $B$ was calculated as the difference between total LpCIII and CIII:NonB.

Internal quality assurance was monitored throughout the study using frozen pools at a minimum of two levels for each apolipoprotein. External quality assurance was assessed by the laboratory's participation in the CDC-IUIS apolipoprotein surveys for AI, B and $\operatorname{Lp}(\mathrm{a})^{40,41}$.

\section{Statistical analysis}

All the data are expressed as mean(s.d.). The data of the athletes and controls were compared by employing a two-tailed independent $t$ test.

\section{Results}

As shown in Table 2, the mean plasma total cholesterol $(P<0.05)$, LDL-cholesterol, apo AII and E were significantly lower $(P<0.01)$ in the athletes
Table 2. Fasting plasma lipid, lipoprotein and apolipoprotein levels in male athletes and controls

\begin{tabular}{lccc}
\hline & Athletes & Controls & $P$ \\
\hline Lipids and lipoproteins $\left(\mathrm{mg} \mathrm{dl}^{-1}\right)$ & & & \\
Total cholesterol & $107(20.3)$ & $129(24.1)$ & $<0.05$ \\
Triglyceride & $66(13.7)$ & $58(24.1)$ & n.s.* \\
HDL-cholesterol & $44(13.7)$ & $45(11.0)$ & n.s. \\
VLDL-cholesterol & $13(2.7)$ & $12(4.8)$ & n.s. \\
LDL-cholesterol & $49(20.0)$ & $73(22.0)$ & $<0.01$ \\
Apolipoproteins $\left(\mathrm{mg} \mathrm{dI}^{-1}\right)$ & & & \\
Al & $149(44.1)$ & $130(23.4)$ & n.s. \\
All & $20(6.5)$ & $38(9.8)$ & $<0.01$ \\
B & $69(12.8)$ & $70(13.4)$ & n.s. \\
Lp(a) & $12(6.7)$ & $15(10.0)$ & n.s. \\
E & $2(1.3)$ & $5(2.1)$ & $<0.01$ \\
LpAl & $43(11.0)$ & $38(5.9)$ & n.s. \\
CIII & $20(5.9)$ & $16(3.9)$ & $<0.05$ \\
CIII: B & $11(5.6)$ & $6(2.6)$ & $<0.01$ \\
CIII: NonB & $9(5.6)$ & $10(4.1)$ & n.s. \\
CVD Risk indices & & & \\
Total cholesterol: HDL-cholesterol & $2.61(0.78)$ & $3.05(0.95)$ & n.s. \\
LDL-cholesterol: HDL-cholesterol & $1.28(0.70)$ & $1.76(0.78)$ & n.s. \\
Apo B:Al & $0.49(0.15)$ & $0.56(0.15)$ & n.s. \\
\hline
\end{tabular}

Values are mean(s.d.); ${ }^{*}$ n.s., Not statistically significant $(P>0.05)$

than in the controls. The means of plasma CIII $(P<$ $0.05)$ and CIII:B $(P<0.01)$ were significantly higher in the athletes than the controls, while the mean values of plasma triglycerides, HDL-cholesterol, apo AI, B, Lp(a), LpAI and CIII:NonB in the athletes were not significantly different $(P>0.05)$ from those of the controls.

Furthermore, the means of TC:HDL, LDL-cholesterol: HDL-cholesterol, and apo B:AI, respectively, were also lower than those of the controls. However, the differences were not statistically significant $(P>$ 0.05).

\section{Discussion}

The roles played by the various lipid, lipoprotein and apolipoprotein fractions in the development of coronary heart disease have been documented in the literature. However, few reports 27,28 are available on this subject in black athletes. The present study is, therefore, important. It shows that the levels of antiatherogenic apo $\mathrm{AI}$ and LPAI, and the atherogenic lipids total and LDL-cholesterol, apo B and $\mathrm{Lp}(\mathrm{a})$ were favourable in the athletes, an indication that physical activity may be associated with favourable changes in the lipid and apolipoprotein profiles of young and healthy Nigerian athletes. This observation is similar to an earlier finding in male untrained Nigerian university students ${ }^{28}$ and some other reports on Caucasians ${ }^{8,12-14,20}$.

In people engaged in training programmes, both acute responses and chronic adaptation may contribute to the respective lipoprotein profiles ${ }^{42}$. Physical training has been shown to produce favourable changes in the lipid and lipoprotein profiles ${ }^{12-15}$; some reports, however, did not show apparent changes, most especially in women ${ }^{16,17,43}$. This has been attributed to changes in endogenous sex 
hormones during the exercise training periods and also probably because premenopausal women start with a higher pretraining HDL cholesterol level than men ${ }^{44}$.

The inverse association between physical activity and CVD incidence appears to relate at least in part to the effect on HDL cholesterol ${ }^{8,13,16,20,46}$. In men, increased physical activity usually results in an increase in HDL level $16,20,45,46$, some researchers, however, found no change in HDL level ${ }^{47,48}$. This may be due to changes in the distribution of HDL subfractions without alteration of total HDL concentration, or to differences in experimental design. In this study, there was also no apparent difference between the mean HDL level in the male athletes when compared with the controls. This observation may be due to the fact that the athletes are mostly involved in anaerobic sports. The LDL-cholesterol fraction was, however, significantly lower $(P<0.01)$ in the athletes.

The mean total triglycerides in athletes in this study tended to be higher, although non-significantly, than the control value. This may also be due to the reported acute nature of the triglyceride lowering effect of exercise, moreover, the pre-exercise triglyceride level tends to influence its response to exercise $^{8}$.

Overall, it is expected that the athletes will be more physically fit than the controls. Using the CVD predictor ratios TC:HDL, LDL-cholesterol: HDLcholesterol, and apo B:AI, the athletes showed a favourable, but statistically insignificant, decreased risk of CVD when compared with the controls. It thus appears that exercise decreases TC:HDL ratios in Nigerians by lowering LDL-cholesterol. In Caucasians, exercise tends to lower TC:HDL ratios by raising HDL-cholesterol ${ }^{13,15,20,45,46}$, as well as lowering LDL-cholesterol ${ }^{9}, 12,16$.

While a cause and effect conclusion cannot be drawn from our present data, our findings revealed that regular exercise may be associated with desirable lipid, lipoprotein and apolipoprotein profiles in Nigerian athletes. The antiatherogenic apo $\mathrm{AI}$ and LpAI and the atherogenic total and LDL-cholesterol, apo $B, L p(a)$ were favourably affected. Furthermore, the CVD risk predictor ratios: TC:HDL, LDLcholesterol:HDL-cholesterol, and apo B:AI showed an insignificant decrease in the athletes. Based on our findings, we conclude that increased physical activity level may reduce CVD risk in healthy Nigerians.

\section{Acknowledgements}

We are indebted to the Director and Technologists of the Medical Research Laboratories, Cincinnati, Ohio, USA for their technical assistance in the lipid and apolipoprotein assays, and to Donalee Z. Bewley for helping in the preparation of this manuscript. We also gratefully acknowledge the critical review of the manuscript and valuable advice of Dr Joseph A. Balogun.

\section{References}

1 Castelli WP, Doyle JT, Gordon T et al. HDL-cholesterol and other lipids in coronary heart disease: the cooperative lipoprotein phenotyping study. Circulation 1977; 55: 767-72.
2 Kannel WB. High-density lipoproteins: epidemiologic profile and risks of coronary artery disease. Am J Cardiol 1983; 52: 9B-12B.

3 Sniderman $\mathrm{AD}$. Apolipoprotein $\mathrm{B}$ and apolipoprotein $\mathrm{AI}$ as predictors of coronary artery disease. Can J Cardiol 1988; 4: 24A-30A.

4 Stein EA. Lipid risk factors and atherosclerosis: what do we measure? Scand I Clin Lab Invest 1990; 50 (Suppl. 198): 3-8.

5 Ross R. The pathogenesis of atherosclerosis - an update. $N$ Engl J Med 1986; 314: 488-500.

6 Fried RE, Levine DM, Kwiterovich PO et al. The effect of filtered-coffee consumption on plasma lipid levels: results of a randomized clinical trial. JAMA 1992; 267: 811-15.

7 Glueck CJ, Hogg E, Allen C, Gartside PS. Effects of alcohol ingestion on lipids and lipoproteins in normal men: isocaloric metabolic studies. Am J Clin Nutr 1980; 33: 2287-93.

8 Haskell WL. The influence of exercise on the concentrations of triglyceride and cholesterol in human plasma. Exerc Sport Sci Rev 1984; 12: 205-44.

9 Martin RP, Haskell WL, Wood PD. Blood chemistry and lipid profiles of élite distance runners. Ann NY Acad Sci 1977; 301: 346-60.

10 Ordovas JM, Schaefer EJ, Salem D et al. Apolipoprotein A1 gene polymorphism in the $3^{\prime}$ flanking region associated with familial hypoalphalipoproteinemia. $N$ Engl J Med 1986; 314: 671-7.

11 Taylor GO, Agbedana EO. A comparative study of plasma high-density lipoprotein cholesterol in two groups of Nigerians of different socioeconomic status. Afr J Med Sci 1983; 12: 23-38.

12 Wood PD, Haskell WL, Stern MP, Lewis S, Perry C. Plasma lipoprotein distribution in male and female runners. Ann $N Y$ Acad Sci 1977; 301: 748-63.

13 Cowan GO. Influence of exercise on high-density lipoproteins. Am J Cardiol 1983; 52: 13B-16B.

14 Schriewer H, Gunnewig V, Assmann G. Effect of 10 weeks endurance training on the concentration of lipids and lipoproteins as well as on the composition of high-density lipoproteins in blood serum. Int J Sports Med 1983; 4: 109-15.

15 Stein RA, Michielli DW, Glantz MD et al. Effects of different exercise training intensities on lipoprotein cholesterol fractions in healthy middle-aged men. Am Heart J 1990; 119: 277-83.

16 Brownell KD, Bachorik PS, Ayerle RS. Changes in plasma lipid and lipoprotein levels in men and women after a program of moderate exercise. Circulation 1982; 65: 477-84.

17 Frey MA, Doerr BM, Laubach LL, Mann BL, Glueck CI Exercise does not change high-density lipoprotein cholesterol in women after ten weeks of training. Metabolism 1982; 31: $1142-6$.

18 Obregon MJ, Jacobsson A, Kirchgessner T, Schotz MC, Cannon B, Nedergaard J. Postnatal recruitment of brown adipose tissue is induced by the cold stress experienced by the pups. An analysis of mRNA levels for thermogenin and lipoprotein lipase. Biochem J 1989; 259: 341-6.

19 Vega GL, Groszek E, Wolf R, Grundy SM. Influence of polyunsaturated fats on composition of plasma lipoproteins and apolipoproteins. J Lipid Res 1982; 23: 811-22.

20 Adner MM, Castelli WP. Elevated high-density lipoprotein levels in marathon runners. JAMA 1980; 243: 534-6.

21 Knuiman JT, West EC. HDL-cholesterol in men from 13 countries. Lancet 1981; ii: 367-8.

22 Onitiri AC, Sander M, Boyo AE. Serum lipids and lipoproteins in healthy Africans. Clin Chim. Acta 1977; 81: 57-61.

23 Ogunnowo PO, Odesanmi WO, Andy JJ. Coronary artery pathology of 111 consecutive Nigerians. Trans $R$ Soc Trop Med Hyg 1986; 80: 923-6.

24 Taylor GO, Barber JB, Jackson MA, Rosch JA, Williams AO. Lipid composition and cerebral vessels in American Negroes, Caucasians and Nigerian Africans: a comparative study. Stroke 1975; 6: 298-300.

25 Williams AO. Atherosclerosis in the Nigerians. J Pathol 1969; 99: 219-35.

26 Williams AO. Coronary atherosclerosis in Nigeria. Br Heart J 1971; 33: 95-100.

27 Adeniran SA, Toriola AL. Effects of different running programmes on body fat and blood pressure in school boys aged 13-17 years. J Sports Med Phys Fitness 1988; 28: 267-73. 
28 Toriola AL. Influence of 12-week jogging on body fat and serum lipids. $\mathrm{Br} J$ Sports Med 1984; 18: 13-17.

29 Thomas AE, McKay DA, Cutlip MB. A nomograph method for assessing body weight. Am J Clin Nutr 1976; 29: 302-4.

30 Steiner PM, Freidel J, Bremner WF, Stein EA. Standardization of micromethods for plasma cholesterol, triglyceride and HDL-cholesterol with the Lipid Clinics' methodology. J Clin Chem 1991; 19: 850.

31 Myers GL, Cooper GR, Winn CL, Smith SJ. The Centers for Disease Control National Heart Lung and Blood Institute Lipid Standardization Program: an approach to accurate and precise lipid measurements. Clin Lab Med 1989; 9: 105-35.

32 Warnick GR, Albers JJ. A comprehensive evaluation of the heparin manganese precipitation procedure for estimating high-density lipoprotein cholesterol. J Lipid Res 1978; 19: 65-76.

33 Friedewald WT, Levy RI, Frederickson DS. Estimation of the concentration of low-density lipoprotein cholesterol in plasma without use of the preparative ultracentrifuge. Clin Chem 1972; 18: 499-502.

34 Stein EA, DiPersio L, Pesce AJ et al. Enzyme-linked immunoabsorbent assay of apoprotein AII in plasma, with use of monoclonal antibody. Clin Chem 1986; 32: 967-71.

35 Stein EA, Kreisberg R, Miller V, Mantell G, Washington L, Shapiro D. Effect of simvastatin and cholestyramine in familial and non-familial hypercholesterolemia. Arch Intern Med 1990; 150: 341-5.

36 Miller JA, Stein EA, Kaplan LA. Development of a competitive binding enzyme-linked immunoabsorbent assay (ELISA) for plasma apoprotein $\mathrm{E}$ using a monoclonal antibody (Mab). Clin Chem 1990; 36: 964.

37 Stein EA, Kumbla L, Miller J, Srivastava L, Kashyap M. Development and evaluation of a competitive ELISA for Lp(a). Clin Chem 1992; 38: 1067.

38 Koren E, Puchois P, Alaupovic P, Fesmire A, Kandoussi A, Fruchart JC. Quantitative determination of two different types of apolipoprotein A-I containing lipoprotein particles in human plasma by an enzyme-linked differential-antibody immunosorbent assay. Clin Chem 1987; 33: 38-43.

39 Curry MD, McConathy WJ, Fesmire JD, Alaupovic P. Quantitative determination of human apolipoprotein CIII by electroimmunoassay. Biochim Biophys Acta 1980; 617: 503-13.

40 Labeur C. CDC-IUIS International Survey of Lp(a). European Atherosclerosis Society Meeting, Brugge, Belgium, May 1990. Abstract No. 26, p. 11.

41 Smith SJ, Cooper GR, Henderson LO, Hannon WH. An international collaborative study on standardization of apolipoproteins A1 and B. Clin Chem 1987; 33: 2240-51.

42 Lokey EA, Tran ZV. Effects of exercise training on serum lipid and lipoprotein concentration in women: a meta-analysis. Int J Sports Med 1989; 10: 424-9.

43 Moll ME, Williams RS, Lester RM, Quarfordt SH, Wallace AG. Cholesterol metabolism in non-obese women. Atherosclerosis 1979; 34: 159-66.

44 Mendoza SG, Carrasco H, Zerpa A et al. Effect of physical training on lipids, lipoproteins, apolipoproteins, lipases, and endogenous sex hormones in men with premature myocardial infarction. Metabolism 1991; 40: 368-77.

45 Streja D, Mymin D. Moderate exercise and high-density lipoprotein cholesterol. JAMA 1979; 242: 2190-2

46 Enger SC, Herbjornsen $\mathrm{K}$, Krikssen J, Fretland A. Highdensity lipoprotein (HDL) and physical activity: the influence of physical exercise, age and smoking on HDL-cholesterol and HDL-total cholesterol ratio. Scand J Clin Lab Invest 1977; 37: 251-5.

47 Dufaux B, Assmann G, Order U, Hoederath A, Hollman N. Plasma lipoproteins, hormones and energy substitution during first days after prolonged exercise. Int J Sports Med 1981; 2: 256-60.

48 Thompson PD, Cullinane E, Henderson LO, Herbert PN. Acute effects of prolonged exercise on serum lipids. Metabolism 1980; 29: 662-5. 